Received:

$1-\mathrm{VII}-2021$

Accepted:

16-IX-2021

Published Online: 29-X-2021

\section{Quantification of Sphingosine-1-Phosphate (S1P) in Patients with Periodontitis Stage II Grade B}

\author{
Cuantificación de esfingosina 1 fosfato en pacientes \\ con periodontitis estadío II grado B
}

María I. García-Parra C.D. ${ }^{\text {; }}$ Matilde Jiménez-Coello Dra²; Bertha A. Carrillo-Ávila M.I.N.E. ${ }^{3}$; Eduardo A. Sauri Esquivel M.04; Víctor M. Martínez-Aguilar Dr55; Elda G. Chávez-Cortéz Dra6

1. Department of Periodontics, Faculty of dentistry, Autonomous University of Yucatan (UADY), Mérida, YUC ZIP 97000, México. https://orcid.org/0000-0002-6712-0571

2. Cellular Biology Laboratory, Regional Research Center "Dr. Hideyo Noguchi", Autonomous University of Yucatan (UADY) Mérida, YUC ZIP 97000, México. https://orcid.org/0000-0002-8802-2049

3. Department of Periodontics, Faculty of dentistry, Autonomous University of Yucatan (UADY), Mérida, YUC ZIP 97000, México. https://orcid.org/0000-0001-5894-4459

4. Department of Periodontics, Faculty of dentistry, Autonomous University of Yucatan (UADY), Mérida, YUC ZIP 97000, México. https://orcid.org/0000-0001-8633-7103

5. Department of Periodontics, Faculty of dentistry. Cellular Biology Laboratory, Regional Research Center "Dr. Hideyo Noguchi” Autonomous University of Yucatan (UADY), Mérida, YUC ZIP 97000, México. https://orcid.org/0000-0003-2188-5293

6. Faculty of Dentistry, Autonomous University of Baja California (UABC), Mexicali Campus, ZIP 21360, México. https://orcid.org/0000-0002-9566-2976

Correspondence to: Dra. Elda Georgina Chávez-Cortéz - geogirna@hotmail.com

ABSTRACT: The aim of this study was the quantification of Sphingosine-1-phosphate (S1P) in periodontal pockets of patients with periodontitis. This is an observational, descriptive, case-control study. Thirty subjects were selected: 15 controls and 15 cases. A periodontal study was conducted following the parameters of AAP 2017 for the diagnosis of periodontal diseases. A sample of saliva and gingival crevicular fluid was obtained from each subject and then analyzed with the Human S1P Elisa kit (MyBioSource \#MBS2516132) accordingly to the manufacturer's instructions, in order to verify the presence of S1P and quantify it's concentration when founded. Results showed a significant difference $(p=0.05)$ between cases and controls. In the case of saliva samples, the concentration of S1P was higher than the ones found in the control group (72.94 ng/mL and $45.12 \mathrm{ng} / \mathrm{mL})$. For GCF, a higher amount of S1P was found in patients with POD $(20.09 \mathrm{ng} / \mathrm{mL}$ and $15.20 \mathrm{ng} / \mathrm{mL})$. This work raises a possible route of bone metabolism, inflammatory process, and identification of periodontitis through oral quantification of S1P, however, future studies are needed. 
KEYWORDS: Periodontitis; Sphingosine-1-Phosphate; Osteoclastogenesis; Inflammation; Saliva; Gingival crevicular fluid.

RESUMEN: El propósito de este estudio fue la cuantificación de Esfingosina-1-Fosfato (S1P) en las bolsas periodontales de pacientes con periodontitis. Estudio observacional, descriptivo de casos y controles. 30 sujetos fueron seleccionados de los cuales 15 controles y 15 casos. Se realizó un estudio periodontal completo siguiendo los parámetros establecidos por la AAP en 2017 para el diagnóstico de las enfermedades periodontales. Se tomaron muestras de saliva y de líquido crevicular gingival de cada sujeto estudiado y se analizaron con el ELISA kit humano para S1P (MyBiosource \#MBS2516132) y de acuerdo con las instrucciones del fabricante, se realizó para cuantificar la presencia d S1P en las muestras estudiadas. Los resultados mostraron diferencia significativa $(p=0.05)$ entre casos y controles. En el caso de las muestras de saliva, la concentración de S1P en controles fue mayor $(72.94 \mathrm{ng} / \mathrm{mL}$ y $45.12 \mathrm{ng} / \mathrm{mL})$. Para Líquido crevicular gingival, se encontró mayor cantidad de S1P en los pacientes con periodontitis $(20.09 \mathrm{ng} / \mathrm{mL}$ y $15.20 \mathrm{ng} / \mathrm{mL})$. Este estudio plantea una posible ruta de metabolismo óseo, proceso inflamatorio e identificación de la Periodontitis a través de la cuantificación oral de S1P, sin embargo se necesitan estudios futuros.

PALABRAS CLAVE: Periodontitis; Esfingosina-1-fosfato; Osteoclastogénesis; Inflamación; Saliva; Líquido crevicular gingival.

\section{INTRODUCTION}

Periodontitis (POD) is defined as the progressive inflammation and destruction of the supporting tissues of the tooth including the gum, periodontal ligament, cement, and alveolar bone, this set is known as periodontium $(1,2)$.

In POD, the presence of periodontal pockets is key to the diagnosis, being these the pathological deepening of the gingival sulcus with a measurement greater than or equal to four $\mathrm{mm}$, originating a loss of clinical insertion (PI) (2).

The product of the local inflammatory response eventually became evident in the gingival sulcus through the Gingival Crevicular Fluid (GCF). It has been detected that in pathological processes the volume of the plasma increases and may slightly change its tone due to the permeability of the vessels present in the epithelial junction that allow the plasma to access the bag $(3,4)$. Analysis of the composition of the GCF can help to identify potential biomarkers of periodontitis (5).

Currently, the term "osteoimmunology" has been introduced, focusing on signaling between cells of the immune system and bone. In the early stages of the infection, the non-specific immune system is activated, later, T and B lymphocytes enter the picture because the T cells that activate macrophages, can indirectly activate osteoclasts and their precursors, and directly to the expression of the receptor-ligand activator of the nuclear factor Kappa Beta (RANKL) (6).

During this inflammatory process, various cytokines are produced that are responsible for regulating the pathophysiology of POD through an interaction between tissue cells and those of the 
immune system; this inflammation together with the participation of interleukins and RANKL leads to the destruction of the periodontium $(7,8)$.

RANKL together with its receptor (RANK) participates in the signaling pathway that regulates the molecular mechanism of the osteoclast formation process, called osteoclastogenesis (9). Current science has shown that in the presence of inflammation the balance of this pathway is altered, causing bone resorption or destruction to exceed new bone formation in patients with POD $(10,11)$.

Sphingolipids are primary elements in the cell membranes, they function for cell signaling and some regulatory processes. The signaling cascade of these lipids includes other bioactive mediators, ceramine, sphingosine, and sphingosine1-phosphate (S1P) (12).

S1P has been identified in bone remodeling processes; inducing the formation of osteoblasts and osteoclasts $(13,14)$. Studies have demonstrated the participation of S1P in inflammatory diseases such as rheumatoid arthritis, and bone homeostasis $(15,16)$. In vitro and in vivo models reported that S1P induces chemotaxis and regulates the migration of osteoclast precursors in bone tissue homeostasis $(17,18)$.

S1P is a bioactive sphingolipid product of sphingosine kinase phosphorylation, which acts as a mediator in many physiological processes including angiogenesis, neurogenesis, inflammation, and lymphocyte trafficking (19). S1P could be a powerful coupling factor between macrophages and osteoclast precursors (20) however, the role it plays in the osteoclastogenesis of POD remains unclear. This study aimed to determine Sphingosine-1phosphate (S1P) concentration through ELISA test from gingival crevicular fluid (LCG) and saliva samples on periodontitis patients.

\section{MATERIALS AND METHODS}

An observational case-control study. 30 patients from 25 to 65 years of age, divided into two groups: 15 systemically healthy patients with POD and 15 systemically healthy subjects with no signs of POD. After voluntary informed consent, patients who attended the specialization area in Periodontics of the Faculty of Dentistry of the Autonomous University of Yucatan were inspected. The periodontal clinical history proposed by Mexican Official Standard (NOM) 013-SSA2-1994 was applied to all participants and a complete periodontal examination was performed, according to the new parameters established by AAP 2017 (21).

Using a calibrated probe from the University of North Carolina (Hu-Friedy, Chicago IL) and recording the data on a standardized periodontogram from the University of Bern; the depth and insertion loss (IP) of all teeth present was measured. All teeth except the third molars were analyzed in 6 sites: the mesiovestibular, vestibular, distovestibular, distolingual, lingual, and mesiolingual areas.

It was subsequently possible to diagnose POD following the criteria recommended in 2017, establishing our patients in Stage II Grade B of this disease (CAL 3-4m, X-ray bone loss of 15-33\%, maximum probing depth of $5 \mathrm{~mm}$, and no tooth loss).

Sample collection was performed one week after the periodontal diagnosis session and patients were asked to abstain from food or liquids and to practice dental hygiene at least one hour before the sample was taken (22). No periodontal treatment was performed before examination (23).

\section{GCF SAMPLE COLLECTION}

In the case of the POD group, the most severe periodontal pocket was located in the 
periodontogram while in controls the first upper molar was sampled. Before the sample was taken, relative isolation was placed with sterile cotton rolls and supervising that the area was free of plaque or dental calculus. The GCF was collected by introducing PerioPaper strips (Oralflow Inc.) into the periodontal sulcus or pocket; approximately $1.2 \mu \mathrm{L}$ of the sample was collected for a standardized period of 30 seconds, avoiding any type of blood or saliva contamination. The strips were then stored in a $1.5 \mathrm{ml}$ Eppendorf tube. All samples that could be contaminated with blood or saliva were removed (24).

\section{SALIVA COLLECTION}

The collection of saliva was taken before the GCF collection. A roll of sterile cotton was placed in the patient's oral cavity, asking him to perform jaw movements as well as swallowing movements for one minute, to stimulate saliva production. The cotton was then placed in a sterile $15 \mathrm{ml}$ Falcon tube (25).

\section{SAMPLE STORAGE AND PROCESSING}

Both samples were stored at $-70{ }^{\circ} \mathrm{C}$ in the freezer until the day of their analysis. Subsequently, the GCF was extracted from the strip by elution of Phosphate Buffered Saline with $0.05 \%$ polysorbate 20 (PBS-T) and centrifuged at 10,000 rpm for 5 minutes at $4{ }^{\circ} \mathrm{C}$, performing this procedure twice until a final volume of $220 \mu$ l was reached (26).

For the extraction of saliva, temperature control and centrifugation at 10,000 rpm were performed for 15 minutes. This procedure was carried out 3 times until a minimum volume of $220 \mu l$ was reached (25).

\section{QUANTIFICATION OF S1P- ELISA PROTOCOL}

The quantification of S1P in GCL and saliva samples from periodontitis patients and control were analyzed by the Enzyme-Linked ImmunosorbentAssay (Human S1P Elisa kit, MyByosourse \#MBS2516132). The ELISA protocol of this study was of a detection range of $3.13-200 \mathrm{ng} / \mathrm{mL}$ and sensitivity of $1.88 \mathrm{ng} /$ $\mathrm{mL}$. In the ELISA plate wells preloaded with human S1P antibody, $100 \mathrm{~mL}$ of saliva and GCF samples were added, and the protocol was followed according to the manufacturer's instructions. The plates were immediately read on the BioRad Model XMark ELISA reader at $450 \mathrm{~nm}$.

\section{ETHICAL ASPECTS}

Endorsed by the Bioethics Committee of the Centro de Investigaciones Regionales "Dr. Hideyo Noguchi" of the Universidad Autónoma de Yucatán, after the appropriate evaluation and acceptance of the proposed protocol by the corresponding body.

\section{STATISTICAL ANALYSIS}

The data was collected in an Excel database (Microsoft Office Professional 2010) and using SPSS for Windows (version 22, Chicago, Illinois USA). The saliva and GCF samples were analyzed through the non-parametric Mann-Whitney U test.

\section{RESULTS}

A total sample of 30 subjects reported no medical condition. The $66.66 \%$ (20 subjects) were women and the remaining $33.33 \%$ (10 subjects) were men, included in the 25-65 age range; also divided into Group 1 (cases) and Group 2 (controls). The average age for Group 1 was 48.86 
years, while for Group 2 it was 41.53 years. The body mass index (BMI) in the case group was 28.28 and 27.18 in controls, which according to the World Health Organization (WHO) is classified as overweight (27). The periodontal characteristics of the study sample are described in Table 1.

Elevated levels of S1P in GCF were detected in patients with POD $(20,0965 \mathrm{ng} / \mathrm{mL})$ compared to the control group $(15,2058 \mathrm{ng} / \mathrm{mL})$, however, no statistically significant difference was detected between the two groups. Elevated levels of S1P in saliva were found in control patients $(72.9457 \mathrm{ng} /$ $\mathrm{mL})$ compared to patients with POD (45.1267 ng/mL), with a statistical significance of $p<0.05$ (Figure 1).

No significant difference was found when comparing the amount of insertion loss with the concentration of S1P in saliva and GCF $(p=0.79$, $p=0.840$ respectively) by Spearman correlation.

Table 1. Periodontal characteristics of the studied sample (Mean \pm Standard deviation)

\begin{tabular}{ccc}
\hline & Group 1 & Group 2 \\
\hline Probing depth * $(\mathrm{mm})$ & $3.24 \pm 1.13$ & $1.75 \pm 0.2948$ \\
$\%$ bleeding $^{*}$ & $35.93 \pm 26.39$ & $3 \pm 3.98$ \\
$\mathrm{Pl}^{*}($ rank $)$ & $-3.5667 \pm 0.99$ & $-1.7867 \pm 0.2972$ \\
& $(-6.2 \mathrm{~mm},-2.3 \mathrm{~mm})$ & $(-2.4 \mathrm{~mm},-1.4 \mathrm{~mm})$ \\
\hline
\end{tabular}

${ }^{*} p<0.05 . P I$, clinical insertion.

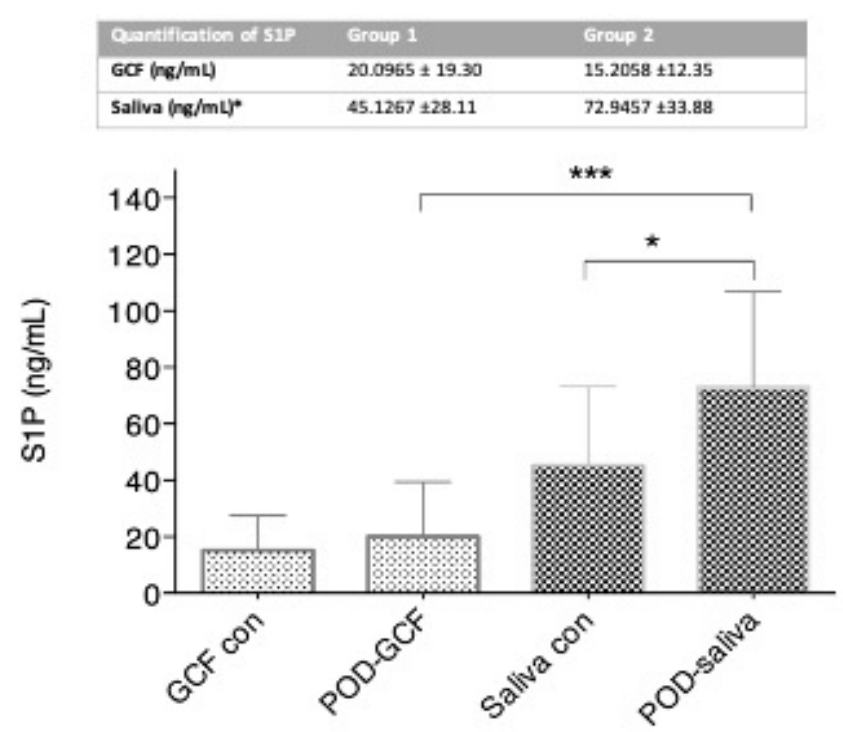

Figure 1. Expression of S1P. Quantification of S1P levels in control groups and periodontal disease. Data are represented as the mean \pm SD. ${ }^{*} p<0.05$. GCF, gingival crevicular fluid; con, control; POD, periodontitis. 


\section{DISCUSSION}

Some regulatory pathways of osteoclastogenesis of alveolar bone have been described, such as RANK-OPG-RANKL; S1P has been identified at a systemic level in diseases such as cancer, arthritis, blood vessel formation, among others. Lately, this sphingosine has started to be mentioned at bone level, however, it has not been widely studied in the loss of alveolar bone characteristic of periodontitis.

Authors mention the activity of S1P in osteoclastogenesis as well as in osteogenesis $(28,29)$, a role that it performs in conjunction with its S1PR1 receptor. Among the main functions of S1P, there is proliferation, migration, and signaling; in 2019, new actions were added such as cytoskeletal rearrangement, inflammation, adhesion, and trafficking of various cells of the immune and vascular systems (30).

As for S1P levels, increased concentration of S1P has been localized in cancer, rheumatoid arthritis, and atherosclerosis. The levels of circulating S1P in the blood are produced by the red blood cells, so the hematocrit value influences their concentration (31).

In the case of bone pathologies, a loss of the balance between S1P-S1PR1 has been observed, which regulates the activities of signaling and chemotherapeutic attraction of osteoclast precursors. When this balance is broken, alterations arise, such as aberrant bone remodeling, inflammatory diseases such as rheumatoid arthritis. In these conditions, excess osteoclastogenic stimulation exceeds new bone formation, resulting in net bone resorption and loss. Xiao et al., reported in a model of periodontitis in rats, the elevation of S1P in the affected site, as well as our results obtained in GCF, also identified induction of chemoattractant activity achieving higher amounts of RANKL (14).
Our study found elevated levels of S1P in GCF in patients with POD concerning controls; one of the justifications for this could be what several authors explain, that when there are high concentrations of S1P and even the higher these are, it induces hyperpermeability of the endothelial barrier causing a loss of integrity of the barrier and increased vascular tone $(14,32)$ (Figure 2); Just what happens in periodontitis, where there is an exudate of substances from the circulation, which crosses the barrier of the junction epithelium causing inflammation.

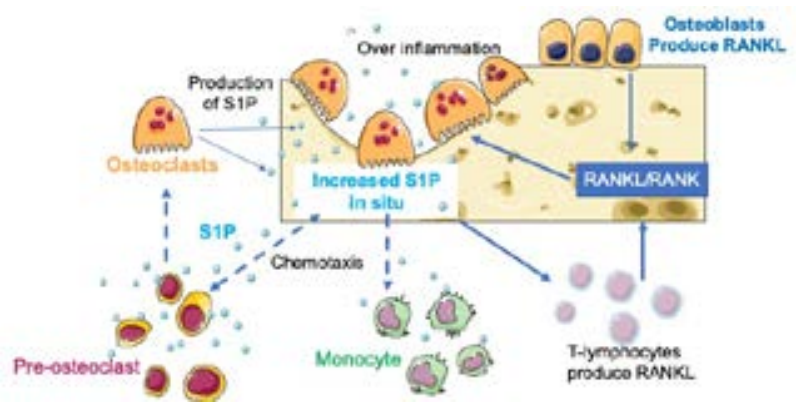

Figure 2. Possible mechanism of action of S1P during inflammation and osteoclastogenic process in POD. Chemotaxis of preosteoclasts, osteoclasts and macrophages are caused by elevated levels of S1P in situ; osteoblasts and immune system cells, such as T cells, contribute to the production of RANKL, which when joined with RANK lead to osteoclast differentiation. Mature osteoclasts produce S1P, which again results in an increase in the amount of sphingosine present at the site, a possible loss of endothelial barrier integrity and consequently local inflammation. Servier Medical ART (C).

On the other hand, the destruction of alveolar bone tissue in periodontitis is characterized by an increase in the activity of osteoclasts, derived from osteoclast precursors, attracted to the site of destruction thanks to S1P. S1P induces the production of RANKL through the osteoblasts and $\mathrm{T}$ lymphocytes, and when these join with RANK they initiate the formation of osteoclasts. Once differentiated, osteoclasts can also produce S1P, creating a bi-directional feed circuit for osteoclastogenesis $(14,33,34)$. This confirms another possible explanation for the high 
concentration of S1P in the gingival crevicular fluid of patients with POD.

S1P signaling is critical for modulating the migration of monocytes and macrophages from the bloodstream to affected bone and bone tissues. These monocytes and macrophages are known as osteoclastic precursors, leading to bone loss $(16,34)$.

In saliva, our study reveals high concentrations of S1P in control patients over patients with POD. Among the main components of saliva in healthy patients, there is a high proportion of glycoproteins, such as mucins, proline, immunoglobulins (lg), agglutinins, lactoferrin, cystatins, and lysozyme (35). The main type of immunoglobulin secreted in the saliva is Immunoglobulin A $(\lg A)(36)$.

Akey relationship has beenestablished between S1P and IgA, as sphingosine acts on the versatile pathways of production of this immunoglobulin at the level of intestinal fluids (37). Saliva, also being a body fluid, a change in salivary composition between patients with some disease such as POD and healthy patients, may affect the amount of S1P present; this sphingolipid is hydrophobic in nature, not very soluble in water and requires transport proteins for efficient transport and circulation. For example, in plasma, most are transported by high-density proteins and the rest by albumin (24). It is possible that due to maladjustment in the salivary composition and a greater number of microorganisms in the presence of this pathology, a lower amount of S1P could be found.

\section{CONCLUSIONS}

Although no statistically significant difference in LCG was found in this study, higher levels of S1P were observed in patients with periodontitis. While in saliva it was shown that the difference was greater in the control group and significant, we were able to identify that the LCG could be an indicator for the identification of POD through the quantification of S1P, however further studies are required to be able to propose a possible route of bone metabolism, inflammatory process and identification of POD.

\section{AUTHOR CONTRIBUTION STATEMENT}

Conceptualization and Design: M.I.G.P, V.M.M.A and E.G.C.C.

Literature Review: M.I.G.P., V.M.M.A. and E.G.C.C. Methodology and Validation: M.J.C, B.A.C.A, V.M.M.A and E.G.C.C.

Formal Analysis: E.A.S.E and V.M.M.A.

Investigation and Data Collection: M.I.G.P, E.A.S.E and M.J.C.

Resources: V.M.M.A and M.J.C.

Data Analysis and Interpretation: M.I.G.P, V.M.M.A and E.G.C.C.

Writing-Original Draft Preparation: M.I.G.P, V.M.M.A and E.G.C.C.

Writing-Review \& Editing: all authors.

Supervision: all authors.

Project Administration: V.M.M.A, B.A.C.A and M.J.C.

Funding Acquisition: V.M.M.A and M.J.C.

\section{REFERENCES}

1. Barbato L., Francioni E., Bianchi M., Mascitelli E., Brancato L., Tonelli D. Periodontitis and bone metabolism. Clin Cases in Miner Bone Metab. 2015; 12 (2): 174-177.

2. Hajishengallis G. Periodontitis: from microbial immune subversion to systemic inflammation. Nat Rev Immunol. 2015; 15 (1): 30-44.

3. Baeza M., Garrido M., Hernandez-Rios P., Dezerega A., Garcia-Sesnich J., Strauss F., Aitken J.P., Lesaffre E., Vanbelle S., Gamonal J., Brignardello-Petersen R., Tervahartiala T., Sorsa T, Hernandez M. Diagnostic accuracy for apical and chronic periodontitis biomarkers in gingival crevicular fluid: an exploratory study. J Clin Periodontol. 2016; 43 (1): $34-45$ 
4. Bostanci N., Belibasakis G. Gingival crevicular fluid and its immune mediators in the proteomic era. Periodontol 2000. 2018; 76 (1): 68-84.

5. Suchetha A., Shahna N., Sapna N., Darshan B., Apoorva S., Bhat D. Gingival crevicular fluid: A Review of literature. Annals of Dental Specialty. 2018; 6 (2): 211-216.

6. Duvina M., Barbato L., Brancato L., Delle Rose G., Amunni F., Tonelli P. Biochemical markers as predictors of bone remodelling in dental disorders: a narrative description of literature. Clin cases in Miner Bone Metab. 2012; 9 (2): 100-106.

7. Taubman M., Valverde P., Han X., Kawai T. Immune Response: The Key to Bone Resorption in Periodontal Disease. J Periodontol. 2005; 76 (11): 2033-2041.

8. Naruishi K., Nagata T. Biological effects of interleukin 6 on Gingival Fibroblasts: Cytokine regulation in periodontitis. J Cell Physiol. 2018; 233 (9): 6393-400.

9. Wright H., McCarthy H.S., Middleton J., Marshall M. RANK, RANKL and osteoprotegerin in bone biology and disease. Curr Rev Musculoskelet Med. 2009; 2 (1): 56-64.

10. Nagasawa T., Kiji M., Yashiro R., Hormdee D., Lu H., Kunze M., Suda T., Koshy G., Kobayashi H., Oda S., Nitta H., Ishikawa, I. Roles of receptor activator of nuclear factor $\kappa \mathrm{B}$ ligand (RANKL) and osteoprotegerin in periodontal health and disease. Periodontol 2000. 2007; 43 (1): 65-84.

11. Kapasa E., Giannoudis P., Jia X., Yang X. The effect of rankl/opg balance on reducing implant complications. J Funct Biomater. 2017; 8 (4): 42:2-10.

12. Reynolds G.M., Visentin B., Sabbadini R. Immunohistochemical Detection of Sphingosine-1-Phosphate and Sphingosine Kinase-1 in Human Tissue Samples and Cell Lines. Methods Mol Biol. 2018; 1697: 43-56.

13. Meshcheryakova A., Mechtcheriakova D., Pietschmann P. Sphingosine 1-phosphate signaling in bone remodeling: Multifaceted roles and therapeutic potential. Expert Opin Ther Targets.2017; 21 (7): 725-737.

14. Xiao L., Zhou Y., Friis T., Beagley K. and Xiao Y. S1P-S1PR1 Signaling: the "Sphinx" in Osteoimmunology. Front. Immunol. 2019; 10: 1409:1-18.

15. Ishii M., \& Kikuta J. Sphingosine-1phosphate signaling controlling osteoclasts and bone homeostasis. Biochim Biophys Acta. 2013; 1831 (1): 223-227.

16. Yu H., Sun C., Argraves K. Periodontal inflammation and alveolar bone loss induced by Aggregatibacter actinomycetemcomitans is attenuated in sphingosine kinase 1- deficient mice. J Periodont Res. 2016; 51 (1): 38-49.

17. Ishii M., Egen J.G., Klauschen F., MeierSchellersheim M., Saeki, Y., Vacher J., Germain R.N. Sphingosine-1-phosphate mobilizes osteoclast precursors and regulates bone homeostasis. Nature. 2009; 458 (7237): 524-528.

18. Ishii M., Shimazu Y., Meier-Schellersheim M., Germain R. Chemorepulsion by blood S1P regulates osteoclast precursor mobilization and bone remodeling invivo. J Exp Med. 2010; 207 (13): 2793-2798. 
19. Aoki M., Aoki H., Ramanathan R., C. Hait N., Takabe K. Sphingosine-1-Phosphate Signaling in Immune Cells and Inflammation: Roles and Therapeutic Potential. Mediators of Inflamm. 2016; 2016: 1-11.

20. Maceyka M., Harikumar K., Milstien S., Spiegel S. Sphingosine-1-phosphate signaling and its role in disease. Trends Cell Biol. 2012; 22 (1): 50-60.

21. Caton, J., Armitage, G., Berglundh, T., et al. A new classification scheme for periodontal and peri-implant diseases and conditionsIntroduction and key changes from the 1999 classification. J Clin Periodontol. 2018; 45 (20): S1-S8.

22. Dame Z., Aziat F., Mandal R., Krishnamurthy R,1Bouatra S, Borzoui S, et al. The Human Saliva Metabolome. Metabolomics. 2015; 11 (1): 864-83.

23. Leppilahti,J.M.,Hernández-Ríos,P.A., Gamonal, J.A., Tervahartiala, T., Brignardello-Petersen, R, Mantyla, P, Sorsa, T, Hernández, M. Matrix metalloproteinases and myeloperoxidase in gingival crevicular fluid provide site-specific diagnostic value for chronic periodontitis. J Clin Periodontol. 2014; 41: 348-356.

24. Gamonal J., Bascones A., Jorge O., Silva A. Chemokine RANTES in gingival crevicular fluid of Adult patients with periodontitis. J Clin Periodontol. 2000; 27: 675-681.

25. Navazesh, M. Methods for collecting saliva. Ann Ny Acad Sci. 1993; 694 (1): 72-77.

26. Spring Bio Science. Phosphate Buffered Saline with Tween 20 (20x). California. 2012.

27. World Health Organization. Obesity and overweight. OMS April 2020. URL: https:// www.who.int/es/news-room/fact-sheets/ detail/obesity-and-overweight. Accessed May 2020.

28. Sartawi Z., Schipani E., Ryan K., Waeber C. Sphingosine 1-phosphate (S1P) signalling: Role in bone biology and potential therapeutic target for bone repair. Pharmacol Res. 2017; 125: 232-245.

29. Hutami I., Tanaka E., Izawa T. Crosstalk between Fas and S1P1 signaling via NF-kB in osteoclasts controls bone destruction in the TMJ due to rheumatoid arthritis. Jpn Dent Sci Rev. 2019: 55 (1):12-19.

30. Obinata H., Hla T. Sphingosine 1-phosphate and inflammation. Int immunol. 2019; 31 (9): 617-625.

31. Proia R., Hla T. Emerging biology of sphingosine-1-phosphate: its role in pathogenesis and therapy. J Clin Invest. 2015; 125 (4): 1379-1387.

32. Xiao Y., Wu J., Yuan Y., Guo X., Chen B., Huang Q. Effect of moesin phosphorylation on high-dose sphingosine-1-phosphate-induced endothelial responses. Mol Med Rep. 2018; 17 (1): 1933-1939.

33. Keller J., Catala-Lehnen P., Huebner A., Jeschke A., Heckt T., Lueth A., Schilling S., et. al. Calcitonin controls bone formation by inhibiting the release of sphingosine 1phosphate from osteoclasts. Nat Commun. 2014; 5: 5215:1-13.

34. Khavandgar Z., Murshed M. Sphingolipid metabolism and its role in the skeletal tissues. Cell Mol Life Sci. 2015; 72 (5): 959-969.

35. Barembaum S., Azcurra A. La saliva: una potencial herramienta en la Odontología. Rev Fac Odont. 2019; 29 (2): 9-21.

36. Koss M., Castro C., Salúm K., López M. Changes in saliva protein composition in patients with periodontal disease. Acta Odontológica Latinoamericana. 2009; 22 (2): 105-112.

37. Gohda M., Kunisawa J., Miura F., Kagiyama Y., Kurashima Y., Higuchi, M., et al. Sphingosine 1-phosphate regulates the egress of IgA plasmablasts from Peyer's patches for intestinal IgA responses. J Immunol. 2008; 180 (8): 5335 - 5343. 